\title{
PERSPECTIVE
}

\section{Matrix metalloproteinase biology applied to vitreoretinal disorders}

\author{
C S Sethi, T A Bailey, P J Luthert, N H V Chong
}

Matrix metalloproteinases (MMPs) and their inhibitors are believed to have a significant role in a number of vitreoretinal diseases, from proliferative vitreoretinopathy to age related macular degeneration. The aim of this review is to summarise the current knowledge of their involvement in these diseases and to postulate potential therapeutic strategies.

MMPs are a tightly regulated family of zinc dependent endopeptidases that are capable of degrading all components of the extracellular matrix (ECM) and basement membranes. ${ }^{1}$ The ECM is a complex structure that influences the behaviour of its resident cells, and those in the process of migration, by providing specific contextual information. Enzymes that modify the ECM thus have the potential to affect basic cell biology in many physiological and pathological processes. ${ }^{2}$ Remodelling of the ECM must occur with spatial and temporal precision for normal development, morphogenesis, homeostasis, and tissue repair. ${ }^{3}$ As matrix degradation is a prerequisite for malignant invasion and metastasis, it is not surprising that MMP biology has attracted considerable interest, with clinical oncology trials under way in several organ systems. $^{4-7}$ New proteolytic functions are also being defined for these enzymes. These include the degradation of non-matrix macromolecules such as myelin basic protein, inactivation of $\alpha_{1}$ antitrypsin, release of sequestered growth factors from ECM, and cleavage of bioactive molecules from the cell surface. ${ }^{8}$

The tissue inhibitors of metalloproteinases, or TIMPs, are physiological MMP inhibitors that have now been shown to have additional biological activities independent of this primary function. ${ }^{9}$ The functional proteolytic activity of MMPs in a given biological situation is thus depend- ent on the relative concentrations of regulatory TIMP molecules and active MMPs. Excessive MMP activity is associated with matrix degradation and a feature of destructive diseases such as rheumatoid arthritis, osteoarthritis, ${ }^{11}$ dermal photoageing, ${ }^{12}$ periodontitis, ${ }^{13}$ and chronic ulceration. ${ }^{14}{ }^{15}$ Aberrant regulation may also lead to excess matrix deposition, seen in chronic fibrotic disorders, ${ }^{16-19}$ and the formation of scar tissue following injury. $^{20}$

The interphotoreceptor matrix and Bruch's membrane are examples of ocular matrices that undergo slow physiological turnover. Any disruption in the exquisite homeostatic regulation of these structures may thus have a catastrophic effect on visual function. Understanding the control of MMP expression and activation and the cellular source and specific enzymes produced in a given situation, will contribute significantly to our understanding of many retinal disease processes and open new doors for therapeutic intervention.

\section{Structure and biochemistry}

The MMP family comprises at least 18 members in humans, sharing significant sequence homology and a common multidomain organisation. ${ }^{21}$ They have overlapping substrate specificities but patterns of expression are often distinct in different locations, suggesting precision in the control of matrix turnover. They are divided into three main groups with respect to the main activity of the purified enzymes in vitro (Table 1). The collagenases degrade fibrillar collagens type I, II, and III. The gelatinases cleave triple helical type IV collagen molecules at a single site and have high activity against gelatin. The stromelysins

Table 1 Members of the human MMP family*

\begin{tabular}{|c|c|c|c|c|}
\hline & $\begin{array}{l}\text { MMP } \\
\text { designation }\end{array}$ & $\begin{array}{l}\text { Molecular mass } \\
\text { (latent) }\end{array}$ & $\begin{array}{l}\text { Molecular mass } \\
\text { (active) }\end{array}$ & Main substrates \\
\hline \multicolumn{5}{|l|}{ Collagenases } \\
\hline Interstitial collagenase & MMP-1 & 55 & 43 & Collagen types I, II, III, VII, X (fibrillar) \\
\hline Neutrophil collagenase & MMP-8 & 75 & 58 & Collagen types I, II, III (fibrillar), proteoglycan core protein (PCP) \\
\hline Collagenase 3 & MMP-13 & 65 & 55 & Collagen types I, II, III, IV, gelatin, PCP, fibronectin \\
\hline \multicolumn{5}{|r|}{ 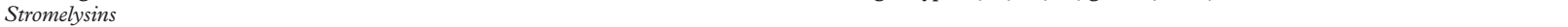 } \\
\hline Stromelysin-1 & MMP-3 & 57 & 46 & Collagen types II, IV, IX, X, XI, procollagen, PCP, fibronectin, laminin \\
\hline Stromelysin-2 & MMP-10 & 57 & 46 & Similar to stromelysin-1 \\
\hline Stromelysin-3 & MMP-11 & 51 & 44 & $\alpha_{1}$ proteinase inhibitor (serpin) \\
\hline \multicolumn{5}{|l|}{ Gelatinases } \\
\hline Gelatinase A & MMP-2 & 72 & 66 & Gelatin, collagen types IV, V, VII, XI, fibronectin \\
\hline Gelatinase B & MMP-9 & 92 & 86 & Gelatin, collagen types IV, V, fibronectin, elastin \\
\hline \multicolumn{5}{|r|}{ 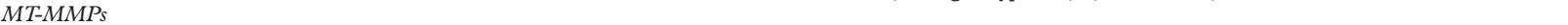 } \\
\hline MT1-MMP & MMP-14 & 64 & 54 & pro-MMP-2, pro-MMP-13, collagens, $\mathrm{PCP}$, fibronectin, tenascin \\
\hline MT2-MMP & MMP-15 & 72 & 61 & Similar to MT1-MMP \\
\hline MT3-MMP & MMP-16 & 66 & 55 & pro-MMP-2 \\
\hline MT4-MMP & MMP-17 & unknown & 54 & 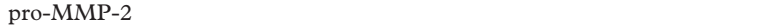 \\
\hline MT5-MMP & MMP-24 & 63 & 62 & $\begin{array}{l}\text { pro-MMP-2. Shed forms of MT5-MMP of } 28 \mathrm{kDa} \text { and } 44-46 \mathrm{kDa} \text { also exist } \\
\text { and have some activity in vitro }\end{array}$ \\
\hline \multicolumn{5}{|r|}{ 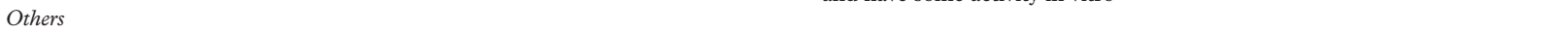 } \\
\hline Matrilysin & MMP-7 & 28 & 20 & Collagen types IV, PCP, fibronectin, elastin, gelatin \\
\hline Metalloelastase & MMP-12 & 54 & 45 & Elastin \\
\hline
\end{tabular}

^Reviewed in references $1,4,22,79$. 
degrade type IV collagen, other collagens with interrupted triple helices, and are also active against laminin, fibronectin, and proteoglycans. ${ }^{22}$

Most members of the MMP family have well conserved structural domains ${ }^{23}$ :

(1) the leader sequence targets the molecule for secretion and is then removed;

(2) the amino terminal propeptide consists of $80-90$ amino acids which are removed extracellularly to activate the latent enzyme;

(3) the catalytic domain contains a zinc ion in the active site that is essential for proteolytic activity. There is a further "structural" zinc ion required to maintain a functionally stable conformation and at least one calcium ion;

(4) the haemopexin-like domain has been shown to have a functional role in substrate binding and interaction with the TIMPs. ${ }^{24}$

The membrane-type MMPs (MT-MMPs) comprise a subgroup that presently consists of five members. They differ in that they are processed to the active form intracellularly. A hydrophobic stretch of some 25 amino acids represents a transmembrane domain at the carboxy terminus and there is a recognition site for furin-like convertases at the end of the propeptide domain. They have been shown to degrade components of the ECM and activate classic MMPs in vitro. ${ }^{25}$ The recently characterised MT5-MMP may contribute to the activation of pro-MMP-2 in tumour tissues in which it is overexpressed and, in contrast with other MT-MMPs, can also be shed from the cell surface as a soluble proteinase. ${ }^{26}$ Abnormal function of such cell surface proteases associated with malignant tumour cells may contribute to their invasive potential. ${ }^{25}$

Two recently cloned human MMPs, MMP-19 and enamelysin (MMP-20), cannot be classified into any of the above subgroups on the basis of structure or substrate specificity. ${ }^{27} \mathrm{MMP}-20$ is expressed during tooth development and has been shown to degrade amelogenin.

\section{REGULATION OF MMP ACTIVITY}

The MMP axis must be highly regulated to avoid excessive tissue destruction, and this is achieved in three ways: transcriptional regulation, ${ }^{28}$ proenzyme activation, ${ }^{23}$ and the action of the TIMPs. ${ }^{29}$ Most MMPs are not constitutively expressed in vivo but can be rapidly induced in response to exogenous signals such as growth factors, cytokines, phorbol esters, and cell-cell or cell-ECM interactions. Exceptions to the rule include MMP-8 and MMP-9, which are stored in the secretory granules of neutrophils and eosinophils, and MMP-7, stored in secretory epithelial cells of exocrine glands. ${ }^{30}$ The 5 '-flanking regulatory region of inducible MMPs contains an AP-1 cis regulatory element in the proximal promoter. Appropriate signals (such as platelet derived growth factor, basic fibroblast growth factor, epidermal growth factor) activate the AP-1 transcription factor complex, composed of c-fos and c-jun proto-oncogene proteins, which binds to the AP-1 cis element to activate transcription of the corresponding MMP gene. ${ }^{31}$ Other moieties, such as IL-4, IL-10, IL-13, and transforming growth factor $\beta$ (TGF- $\beta$ ) can downregulate some MMPs.

Latent MMPs are proteolytically activated in the extracellular space, with the exception of MMP-11 and MT-MMPs, which are activated before secretion by Golgi associated furin-like proteases. Plasmin is an important physiological activator of pro-MMPs and can initiate a cascade of MMP activation at the cell surface. ${ }^{32}$ For example, upon activation of MMP-9 and MMP-3, the latter can activate more MMP-9, and also MMP-1, amplifying the response. Localising this activation machinery on the cell surface, via integrin receptors and MT-MMPs, ensures that the proteolytic response is maximal in the immediate pericellular environment. ${ }^{33}$ Another important, though often overlooked, activation mechanism is via reactive oxygen species released from inflammatory cells. ${ }^{13}$

Activated MMPs can then be specifically inhibited in tissues by forming a 1:1 non-covalent complex with TIMPs, ${ }^{34}$ though inactivation can also occur nonspecifically in plasma by binding to proteins such as $\alpha_{2}$ macroglobulin. The formation of such complexes determines the rate at which physiological factors can activate MMPs. Four TIMPs have been identified in humans ${ }^{35}$ (Table 2). They have 30-40\% sequence homology at the amino acid level and contain two domains held in rigid conformation by six disulphide bonds. One domain is largely responsible for MMP inhibition, while the other can bind to pro-MMPs and may control their autocatalytic activation. They show little difference in their specificity for MMPs, with each TIMP largely capable of inhibiting most MMPs, though TIMP-1 is an ineffective inhibitor of MT-MMPs. TIMP gene expression is also regulated, ${ }^{36}$ which allows coordinate or reciprocal patterns of MMP/ TIMP regulation, depending on the nature of the stimulus and the target cell. ${ }^{37}$ Paradoxically, TIMP-2 is also involved in the activation of pro-MMP-2, to which it binds at the cell surface, along with MT1-MMP, facilitating proteolytic activation of pro-MMP-2 by adjacent MT1-MMP.

TIMPs are expressed by a variety of cells and are present in most tissue and body fluids. TIMP-1, TIMP-2, and TIMP-4 are present in a soluble form, but TIMP-3 is insoluble and bound to the ECM. ${ }^{38}$ There are several reports demonstrating the ability of TIMP-1 and TIMP-2 to promote growth and alter cell morphology in a variety of cultured cell lines. ${ }^{39} 40$ Furthermore, TIMP-3 has been found to be anti-angiogenic ${ }^{41}$ and differs from other TIMPs in inhibiting tumour necrosis factor- $\alpha$ converting enzyme (TACE), suggesting a role in the modulation of inflammation. Clearly, these molecules have important regulatory activities independent of MMP inhibition that require further characterisation.

INTERACTION BETWEEN MMPS, CYTOKINES, AND GROWTH FACTORS

There are many important areas of interaction between the MMP axis and the cytokine network. ${ }^{42-45}$ TGF- $\beta$ inhibits stromelysin and collagenase expression via an upstream element in their promoter sequences referred to as the TGF- $\beta$ inhibitory element. ${ }^{46}$ Interestingly, it also upregu-

Table 2 Properties of tissue inhibitors of metalloproteinases (TIMPs)*

\begin{tabular}{llll}
\hline & TIMP-1 & TIMP-2 & TIMP-3 \\
\hline Chromosome location (human) & Xp11.23-11.4 & $17 \mathrm{q} 2.3-2.5$ & $22 \mathrm{q} 12.1-13.2$ \\
Protein (kDa) & 28 & 21 & 24 \\
mRNA (kB) & 0.9 & $3.5(1.0)$ & $4.5(5.0,2.4,2.6,2.8)$ \\
Expression & inducible & mainly constitutive & inducible \\
Main form of molecule & secreted & secreted & ECM associated \\
\hline
\end{tabular}

$\star$ Reviewed in references 9 and 86

†Numbers in parentheses denote possible splice variants. 
lates TIMP-1 expression. ${ }^{47}$ The combined effect is to prevent the destruction of newly synthesised matrix ${ }^{48}$ and helps explain why elevated levels of TGF- $\beta$ are associated with fibrosis within the eye $\mathrm{e}^{49}$ and elsewhere in the body. MMP mediated degradation of matrix proteins such as decorin can release active TGF- $\beta$ and insulin-like growth factor (IGF) from sequestered stores in connective tissue and complexes with binding proteins. ${ }^{50} 51$

Cytokines and their receptors can also act as substrates for MMPs. Tumour necrosis factor $\alpha(T N F-\alpha)$ is a pro-inflammatory cytokine that can be secreted following cleavage of the membrane bound pro-form by MMPs. ${ }^{52}$ Such "sheddase" or "convertase" action by MMPs may play a part in perpetuating or damping down inflammatory reactions, depending on whether the molecule released is an active protein or a soluble form of receptor. MMP-2, for example, releases an active soluble ectodomain of FGF receptor-1 that may modulate the mitogenic and angiogenic activities of $\mathrm{FGF}^{53}$ It is likely that reprolysin and adamalysin metalloenzymes contribute significantly to this convertase activity at the cell membrane. ${ }^{54} 55$ They have a catalytic site similar to classic MMPs, but a different domain structure, and will not be discussed further as part of this review.

The key issue raised by these findings is that MMP inhibition is likely to do more than just inhibit matrix breakdown in vivo. The functional consequence of such action requires careful characterisation and may produce results that cannot be predicted from the observation of simple systems in vitro.

\section{Role in physiological and pathological processes}

MMPs are determinants of basic cell behaviour in a number of physiological processes. ${ }^{56} 57$ Proteolytic remodelling of the ECM has an "instructional" effect on cellular phenotype that can occur directly via receptor ligation and triggering of appropriate intracellular transduction cascades, or indirectly, by modulating the cellular response to growth factors. For example, ligation of cell surface integrins by matrix components can influence the cellular response to mitogenic signals, suggesting that cell-matrix interactions are important regulators of the cell cycle. Moreover, ECM remodelling has the potential to alter cell phenotype by the release of matrix bound growth factors. Binding proteins for insulin-like growth factor (IGFBP) and latent transforming growth factor $\beta$ (LTBP) can be sequestered in the ECM and released by proteases to influence the behaviour of resident cells. MMP cleavage of functional IGF from complexes with IGFBP has implications for cell proliferation and tissue growth. ${ }^{58}$ Matrix fragments generated through proteolytic remodelling (for example, endostatin and restin) can themselves have a profound influence on cell phenotype, discussed below, with reference to angiogenesis.

Cell migration underlies many biological processes, including inflammation, wound healing, and tumour metastasis. Proteolytic mechanisms do not merely clear a path for migrating cells in these situations, but facilitate crucial cell-cell and cell-matrix interactions, in some cases by revealing cryptic sites previously inaccessible to cell surface receptors. For example, MMP-2 cleaves the $\alpha_{2}$ subunit of laminin- 5 to expose integrin binding sites that trigger cell motility. ${ }^{56}$

The ability of cells to degrade matrix components is thus an essential homeostatic function, but it also forms the basis of a number of disease related processes. These will be discussed more fully below, as they explain the pivotal role of MMPs in ocular pathology and suggest rational approaches for devising new therapies.
INFLAMMATION AND IMMUNITY

Dynamic modulation of cell-cell and cell-matrix interactions must occur between $\mathrm{T}$ lymphocytes and endothelial cells to mount a normal inflammatory response and allow effector cells access to injured tissue. However, inappropriate or unregulated MMP expression can have deleterious effects. Experimental autoimmune encephalomyelitis (EAE) is characterised by multifocal perivascular inflammatory infiltrates in the central nervous system (CNS) and is a disease model of multiple sclerosis (MS), the prototype inflammatory demyelinating disorder of the CNS. ${ }^{59}$ MMP-2 is induced and activated in autoreactive T cells in EAE by $\alpha_{4}$ integrin binding to vascular cell adhesion molecule- 1 on endothelial cells. ${ }^{5657}$ Activated MMPs elaborated by migrating lymphocytes may then process the ECM to an "active" form (analogous to endothelial activation), facilitating further recruitment. MMP dependent cleavage of the transmembrane domain of TNF- $\alpha$ contributes to the release of this proinflammatory cytokine and enhances neuroinflammation. Moreover, MMPs modulate blood-brain barrier leakage ${ }^{60}$ and have been shown to degrade myelin basic protein in vitro, widely considered to be an important autoantigen in MS. It has thus been postulated that MMPs may generate immunogenic fragments of host proteins as "remnant antigens" to drive autoimmune inflammatory processes. Suppression of EAE induction and reversal of clinical changes on treatment with a broad spectrum MMP inhibitor suggest that MMPs are contributing directly to tissue damage in this disease model. ${ }^{59}$ Downregulation of trans-basement membrane migration of T lymphocytes by inhibition of their MMP-9 activity is likely to be a major mechanism by which interferon beta prevents clinical progression in MS patients. ${ }^{61}$

Leucocytes, particularly macrophages and polymorphonuclear leucocytes (PMNs), are a major source of MMP production. ${ }^{62}$ Our colleagues in oral medicine and dentistry have more ready access to biological samples and have established a direct causative role for elevated leucocyte derived collagenase in the pathology of periodontal disease. ${ }^{13}$ The inflammatory process of periodontitis is initiated by subgingival microflora, but the destruction of tooth supporting tissue derives from the host response to these organisms. MMP-8 (neutrophil collagenase) is elevated slightly in simple gingivitis, but present mostly in its latent form, in both tissues and gingival crevicular fluid (GCF). During periodontitis, the levels rise markedly and are activated by host and microbial derived proteases and reactive oxygen species from triggered PMNs. The levels in GCF fall with successful conventional treatment, so active MMP-8 is not only a target for therapy, but also a marker of disease severity, which has led to the development of an immunochromatographic dipstick test for MMP-8 that can be performed in the office. ${ }^{13}$ Subantimicrobial dose doxycycline (SDD) is the first drug acting as an MMP inhibitor to obtain US Food and Drug Administration approval, for treatment in adult periodontitis. ${ }^{63}$ Marketed under the trade name Periostat (CollaGenex Pharmaceuticals Inc, Newtown, PA, USA), it reduces tissue destruction by direct MMP inhibition and also by preventing the influx of inflammatory cells across basement membranes, as discussed above in suppression of EAE.

Clearly, these observations suggest that MMPs can be active agents, and not merely passive markers, of tissue damage. But are MMPs always involved in the initiation of tissue damage or can their presence indicate an attempt at physiological repair? Numerous reports have suggested a role for MMP-3 in the pathology of rheumatoid arthritis, with levels three times higher than controls, and correlation with disease activity. However, in systemic lupus ery- 
thematosus, the prototype autoimmune disease, serial measurements of MMP-3 do not correlate with fluctuation in disease activity scores, suggesting that this MMP may not be directly involved in tissue damage, but may be participating in a later phase of inflammation, perhaps involved with tissue repair. ${ }^{64}$ So, MMP inhibitors may be beneficial in the early phases of some diseases, when the MMP activity is predominantly destructive, but later in the disease course the participation of MMPs in repair may actually be a desirable effect.

MMPs are capable of binding to connective tissue matrix, so local production in disease does not necessarily translate into a proportional increase in plasma levels. Comparisons between clinical studies are often difficult, owing to analytical variations. Enzyme linked immunosorbent assay (ELISA) measurements can be higher with diluted samples than undiluted plasma, because of reduced inhibitory effects of specific or non-specific inhibitors or matrix components, so accurate comparisons can only be made between samples at equivalent dilution. ${ }^{65}$ Plasma levels are more reliable than serum levels as they exclude MMPs and TIMPs released from platelet activation and in vitro neutrophil degranulation.

MMPs are expressed in $\mathrm{T}$ cells and macrophages but there has been little evidence for their role in specific immune responses. "Knockout" mice, deficient in specific genes, are providing insights into potential roles for MMPs in these complex phenomena. In a DNFB induced model of contact hypersensitivity (CHS), ${ }^{8}$ the antigen is processed and taken up by Langerhans cells in the suprabasal epidermis, and transported via dermal lymphatics to $\mathrm{T}$ cell rich areas of regional lymph nodes. Naive cells presented with the antigen proliferate to form a specific $T$ cell population that on subsequent challenge will migrate to the challenge site and release pro-inflammatory cytokines to attract other inflammatory cells. By applying DNFB to the dorsal surface of the ear, the ear thickness can subsequently be used as an index of inflammation. MMP-3 knockouts exhibit a markedly impaired CHS response to topical DNFB, though non-specific inflammatory responses to cutaneous irritants remain normal. MMP-9 knockouts exhibit a prolonged inflammatory reaction, accompanied by a lack of IL-10 production at the challenge site.

Mast cells have also been shown to produce MMP-9, ${ }^{66}$ and inhalation of corticosteroids reduces submucosal expression of MMP-9 in asthmatics. As interest intensifies in the potential immunomodulatory roles of MMPs, we are likely to see advances in our understanding of allergic disorders of the anterior segment, as well as presumed immuno-inflammatory disorders of the posterior segment.

\section{WOUND HEALING}

Classic, cutaneous wound healing is characterised by haemostasis, re-epithelialisation, granulation tissue formation and remodelling of the ECM. Inappropriate or failed wound healing represents a major healthcare burden, in which excess proteinase activity has been implicated. Tissue injury produces a fibrin-rich provisional matrix. Cell migration through this scaffold utilises fibrinolytic (plasminogen activator) and proteolytic (MMP) systems. ${ }^{67}$ Subsequent tissue repair can be divided into three phases: the acute inflammatory response, cellular proliferation, and remodelling of ECM.

Healing by primary intention involves surgical approximation of wound edges, using sutures to maintain tensile strength during repair. MMPs are unlikely to have much part to play in this scenario. Healing by secondary intention, however, requires epidermal keratinocyte migration over a denuded surface, which begins within hours of injury. ${ }^{8}$ Migration off basement membrane and onto dermal matrix brings the $\alpha_{2} \beta_{1}$ integrin receptors on these cells into contact with type I collagen and triggers transcription of MMP-1 (collagenase-1), MMP-9, ${ }^{68}$ and MMP-10. The epithelium further away from the healing edge of the wound expresses MMP-3, perhaps to remodel newly formed basement membrane. MMP-1 denatures fibrillar collagen type I and exposes cryptic sites in the ECM that facilitate migration.

As new basement membrane is synthesised, MMP-1 expression is suppressed and epithelial interactions with the basement membrane are stabilised. This occurs through hemidesmosomes forming within keratinocytes, linking them to anchoring fibrils of the subtending dermis, induced by remodelled ECM components. ${ }^{8}$ It is clear, therefore, that appropriate wound healing is accompanied by a temporally regulated increase in MMP activity, but that there are stop signals to reduce MMP production once reparative cells have completed their tasks. Chronic, non-healing ulcers demonstrate increased levels of MMPs, which may partly be due to the lack of appropriate stop signals normally provided by the presence of appropriate repair matrix. The elevated MMP level is thus a primary indicator that the wound bed is failing to heal, and the excess proteinase activity can then cause further tissue damage. ${ }^{69}$

Recent studies have also demonstrated that, while TIMP-1 and TIMP-3 are found in proliferating keratinocytes in normally healing wounds, they cannot be detected in chronic ulcers. ${ }^{70}$ This may contribute to excessive net proteolytic activity and failure to heal the wound bed. What we do not yet know is whether MMP inhibitors can be of use in chronic, failed wound healing, and whether the systemic use of such agents in other applications will interfere with normal re-epithelialisation in wounds that heal by secondary intention. Ophthalmic surgical intervention will also elicit a modified form of wound healing, which may have direct visual sequelae if there is abnormal matrix deposition, or scar contraction involving critical visual structures such as the retina. This is discussed below with reference to proliferative vitreoretinopathy, and other authors have implicated MMPs and TIMPs in subconjunctival healing following trabeculectomy. ${ }^{71}$

\section{ANGIOGENESIS}

MMPs and TIMPs have complex regulatory activities in angiogenesis, which involves the degradation of basement membrane, endothelial cell migration, capillary tube formation and endothelial cell proliferation. ${ }^{72}$ The importance of MT-MMPs in this process is becoming apparent, and is hardly surprising, as it enables endothelial cells to restrict proteolytic activity to the pericellular milieu, retaining surrounding matrix for structural support. ${ }^{33}$ Whatever the "primary" stimulus in physiological or pathological angiogenesis (for example, hypoxia, growth factors) the MMP-TIMP axis is utilised as an effector pathway to direct the cellular processes involved. It is therefore to be expected that neovascularisation is associated with changes in resting levels of MMPs and TIMPs. In pathological neovascularisation, therapy may be directed against the primary stimulus or the effector pathway. If the exact nature of the primary stimulus is not known, then the effector pathway becomes an attractive target for intervention.

Several groups have documented the anti-angiogenic effects of MMP inhibitors, ${ }^{73}$ which have therapeutic potential for angioproliferative disorders such as proliferative diabetic retinopathy. The anti-angiogenic effect of TIMPs may be through downregulation of MMPs required for endothelial cell migration and invasion, or direct suppres- 
sion of these cells: TIMP-2 has been shown to inhibit basic fibroblastic growth factor driven endothelial cell proliferation $^{74}$ and TIMP-3 inhibits endothelial cell motility. The role of MMPs as processors of angiogenic modulators is also attracting considerable interest. ${ }^{75}$ Macrophage metalloelastase (MMP-12) can process angiostatin, a 38 $\mathrm{kDa}$ internal fragment of plasminogen, to its active anti-angiogenic form. ${ }^{73}$ It is a potent inhibitor of endothelial cell proliferation and induces apoptosis. A proteolytic fragment of MMP-2, termed "PEX", is angiostatic by inhibiting the association of MMP-2 with an integrin receptor on vascular endothelial cells. ${ }^{76}$ The accumulation of PEX in developing retinal vessels suggests the presence of a regulatory mechanism that might be exploited to halt abnormal neovascularisation. Moreover, bioactive fragments released during ECM remodelling, such as endostatin and restin (carboxy terminal fragments of collagen XVIII and XV, respectively), strongly suppress neovascularisation by antiproliferative, antimigratory, and apoptotic mechanisms. $^{57}$

The role of vascular endothelial growth factor (VEGF) in angiogenesis is well established, but it may also induce MMP production. ${ }^{77}$ Interestingly, VEGF immunostaining as a marker of neoangiogenesis has been found to be indicative of aggressiveness in serous ovarian tumours, and correlates closely to the presence of MMP-2. ${ }^{78}$ Malignant tumours are angiogenesis dependent diseases, as primary tumour growth, invasion, and metastasis all require neovascularisation.

\section{TUMOUR INVASION AND METASTASIS}

Remodelling of the surrounding matrix permits local tumour cell growth, following which MMPs can facilitate tumour cell invasion and metastasis by degrading ECM barriers, ${ }^{79}$ modulating cell-cell and cell-matrix adhesions and promoting angiogenesis. Metastatic disease is responsible for the majority of cancer related deaths, so understanding the mechanisms behind tumour invasion and metastasis is key to devising new therapies aimed at limiting tumour spread. However, considerable care must be taken in interpreting the two main sources of data on putative roles for MMPs in malignant disease-namely, animal models and studies on human pathological specimens.

There are several potential pitfalls in developing antimetastatic treatments on the basis of animal models. ${ }^{80}$ Firstly, cell proliferation tends to occur more rapidly in primary and metastatic tumours in animals and there is usually less local invasion, resulting in pseudocapsule formation. Secondly, the MMPs are produced by experimental cancer cells rather than the stromal cells. In human pathology, the carcinoma cells produce a factor, EMMPRIN (Extracellular Matrix MetalloPRoteinase INducer) which induces stromal fibroblasts to produce MMPs that are then sequestered by the cancer cells. MMP-7 (matrilysin) is the main exception, being produced by carcinoma cells rather than stromal cells. ${ }^{81}$ Thirdly, experimental cell lines have been selected by in vitro growth characteristics and tend to have more frequent and more bizarre chromosomal abnormalities than human cancers arising spontaneously in vivo. Finally, there is more central necrosis in experimental tumours, suggesting that angiogenesis is a less prominent feature, or at least, cannot "keep up" with tumour growth.

Most studies on human tissue merely reveal increased total MMP expression in cancer versus normal tissue, rather than active MMPs themselves, and do not comment on the potential importance of enzyme-inhibitor complexes. Nevertheless, MMP activity has been linked to the invasive potential of systemic tumours in a number of studies, prompting immunohistochemical investigations to establish whether these enzymes may be predictive of tumour stage and survival time. ${ }^{82}$ MMP-11 (stromelysin-3) was recently identified as an independent prognostic factor for reduced disease free survival in breast carcinoma ${ }^{83}$ and a similar association has been described for MMP-2 immunoreactive protein in melanoma cells of primary skin melanoma. ${ }^{84}$ It is difficult to prescribe an exact role to these MMPs without knowing the nature of the preferred substrates in vivo, but MMP-11 does cleave and inactivate serpins such as $\alpha_{1}$ antitrypsin, and may thus potentiate the action of other proteinases such as urokinase-type plasminogen activator. ${ }^{85}$ Such observations have supported the use of synthetic MMP inhibitors in numerous clinical trials for cancer currently in progress. However, such pathological findings are by no means universal, perhaps due to technical limitations in our ability to detect active MMPs reliably in tissue extracts. The role of TIMPs in tumour progression is complex and paradoxical, reflecting the bimodal function of TIMPs as inhibitors of MMPs, but also facilitators of cell surface activation cascades. ${ }^{86}$ Several mechanisms could explain a tumour suppressor effect. First is their anti-angiogenic activity, though this has yet to be established for tumours in vivo. Secondly, by preventing the degradation of growth factor binding proteins by MMPs in the ECM, TIMPs may limit the bioavailability of growth factors such as TGF- $\beta$ and IGF-II to the tumour cells. Thirdly, by limiting proteolysis of the tumour ECM, they may promote encapsulation. New data support a further, indirect level of control, through maintenance of the integrity of the ECM, which is known to influence basic cell behaviour, including growth, differentiation, and apoptosis. Exogenous TIMP-2 inhibits the growth of human melanoma cells in the presence of intact fibrillar collagen, but this effect is lost if MMPs derived from these cells degrade fibrillar collagen, in the absence of excess TIMP-2. The anti-proliferative effect involves upregulation of the cyclin dependent kinase inhibitor p27, which occurs when cells encounter intact ECM and blocks cell cycle progression. ${ }^{87}$ Transfection of the TIMP-1 gene into melanoma cell lines has resulted in reduced invasive and metastatic potential, ${ }^{88}$ and overexpression of TIMP-1 in transgenic mice can inhibit the growth of primary tumours. ${ }^{89}$

However, evidence also exists to support a tumour promoting activity of TIMPs. In colon cancer and non-Hodgkin's lymphoma, TIMP-1 expression is a positive index of malignant progression. ${ }^{87}$ In bladder and breast cancer, TIMP-2 is an unfavourable prognostic indicator. Are there any mechanisms to account for such observations? TIMP-2 can act as an adaptor molecule between proMMP-2 and MT1-MMP at the cell surface, enhancing the generation of active MMP-2 which might then facilitate invasion of the basement membrane. The TIMPs can also stimulate the growth of a large variety of normal and malignant cells in vitro and TIMP-1 has also been shown to suppress apoptosis of malignant Burkitt cells. ${ }^{87}$ We will understand more if a putative "TIMP receptor" can be found at the cell surface, with characterisation of the signalling pathways involved in these functions.

Whether TIMPs suppress or promote tumours may depend on many factors, such as local concentration, pericellular distribution, and association with proMMPs. Perhaps at low concentrations, TIMPs promote tumour cell growth and stimulate proMMP-2 activation by MT1MMP, while at higher doses they predominantly suppress invasion. It may be that the MMP/TIMP ratio will prove more informative than either measurement alone, an elevated ratio having been correlated with aggressive 
phenotype in pancreatic carcinoma..$^{90}$ At present, there are too many unanswered questions for the therapeutic use of TIMPs in cancer and it will take a lot more work to unravel the paracrine regulation of MMPs in tumour cell biology.

\section{MMPs and TIMPs in vitreoretinal diseases}

The posterior segment provides a unique environment for viewing the evolution of wound healing, angiogenesis, carcinogenesis, and degenerative processes. However, as biological sampling is not straightforward, with specimens often obtained at the end stage of disease processes, there are many unanswered questions regarding the cellular source of MMPs and TIMPs in vitreoretinal diseases and their role in physiological and pathological processes.

Human tissue and cell culture studies suggest that MMPs and TIMPs may have a role in normal retinal homeostasis. Plantner and colleagues have demonstrated the presence of MMP-1, MMP-2, MMP-3, MMP-9 and TIMP-1, TIMP-2, and TIMP-3 in human interphotoreceptor matrix (IPM) and vitreous, using western blot analysis. ${ }^{91}$ Subsequent observations suggest that MMP-2 and TIMP-1 produced by the retinal pigment epithelium (RPE) are secreted from the apical surface bordering the IPM. ${ }^{92}$ MT1-MMP has been demonstrated in retina, vitreous, and choroid, where it may play a part in activating pro-MMP-2. ${ }^{93}$ TIMP-3 has been identified as an ECM associated component of Bruch's membrane and is discussed more fully below.

These investigations have led to studies of human pathological material to investigate whether MMPs and TIMPs may have pathogenic significance in disorders of the posterior segment. For this to be established, the candidate enzyme should be present in diseased tissue, at a level proportional to disease severity. Its biological function should have a plausible role in the aetiology of the disease, and inhibiting this function should modify or abrogate the disease process. With this in mind, we will now discuss those disorders where a significant body of evidence exists to suggest a pathogenic role for these molecules, even if all the aforementioned criteria cannot yet be satisfied, on the basis of present knowledge.

\section{PROLIFERATIVE VITREORETINOPATHY}

Proliferative vitreoretinopathy (PVR) occurs in $5-10 \%$ of all retinal detachments and is the commonest cause of anatomical failure in retinal detachment surgery. ${ }^{94}$ PVR may be viewed as a maladapted wound healing phenomenon in which cellular proliferation occurs on both surfaces of the detached neuroretina, the posterior vitreous face and within the vitreous base, with the formation of contractile periretinal membranes. ${ }^{94}$ Such contraction is likely to be an important mechanism in preventing break closure in detached retina with PVR, and Scott and co-workers have shown that MMP activity is a determinant of cell mediated collagen contraction in vitro. ${ }^{95}$ Many growth factors and cytokines have been proposed as initiators of the cell proliferation, migration, matrix elaboration, and contraction that characterise PVR, making specific molecular inhibition an unreliable therapeutic proposition. As each of these processes is MMP dependent, this family of enzymes may represent a final common pathway in the evolution of PVR that may be more amenable to manipulation. We have discussed above that a temporally coordinated and spatially controlled increase in specific MMP activity is a feature of normal wound healing processes, and that failure to regulate this activity can be detrimental to healing.

MMPs and TIMPs have been demonstrated in subretinal fluid and vitreous, ${ }^{96-98}$ with pro-MMP-2 found constitutively in most studies. The cellular source of
MMPs and TIMPs in the vitreous is not known. Vitreal hyalocytes may be capable of producing these enzymes, but we can still detect MMPs and TIMPs in the vitreous cavity fluid of vitrectomised eyes (unpublished observation). It is noteworthy that the major cellular constituents of PVR membranes, such as RPE cells, glial cells, fibroblasts and inflammatory leucocytes have all been shown to produce MMPs and TIMPs in vitro, the profile varying with cytokine or growth factor stimulation. ${ }^{99-101}$ Limb and coworkers also report detection of active and latent forms of MMP-1 and MMP-2 by immunohistochemistry, in epiretinal and subretinal membranes of PVR. ${ }^{102}$ Vitreous levels are likely to represent proteins produced by retinal and periretinal tissues, as well as leucocytes derived from breakdown of the blood-retinal barrier and cells that have entered the vitreous cavity by transretinal migration or mechanical dispersal. Vitreous levels of these proteins may thus represent the potential for adverse pathological sequelae, in the same way that leaching of MMPs from tissues to the blood stream in patients with biologically aggressive cancer provide plasma markers that might be useful for predicting metastases. ${ }^{64}$

Interpretation of vitreous levels of MMPs requires data on active rather than total protein levels, and information on the level of inhibitory TIMP proteins present, factors that have not been addressed satisfactorily in studies to date. Moreover, given that we expect a proportion of these proteins to be derived from breakdown of the blood-retinal barrier, it is important to investigate whether elevated levels of a particular enzyme correlate with a marker of blood-retinal barrier breakdown, such as total protein concentration. In viral meningitis, TIMP-1 is upregulated in the CSF, but correlates with total protein concentration, and therefore cannot be excluded as a passive circulatory derivative from blood-brain barrier breakdown. ${ }^{103}$ Reduced oxygen tensions may be another factor contributing to elevated TIMP-1 in PVR (and proliferative diabetic retinopathy), as the TIMP-1 promotor contains a hypoxia response element. ${ }^{104}$ The ophthalmic literature contains reference to elevated TIMP-1 as pathogenic in PVR, with no reference to blood-retinal barrier integrity or oxygen tensions. ${ }^{97}$ However, total MMP activity, measured in a peptide substrate cleavage assay, appears to correlate with total TIMP-1 levels in uncomplicated retinal detachment, but this correlation is lost and the total MMP activity is significantly higher in retinal detachment complicated by PVR. ${ }^{105}$ This would suggest that an MMP/TIMP imbalance may be associated with abnormal wound healing processes in PVR.

Vitreous levels of MMPs might not be a direct representation of what is occurring at the tissue level, but if we consider the posterior segment as the "wound healing environment" in PVR, they might conceivably be indicators of adverse outcome, as in non-healing wounds elsewhere in the body, discussed above. It is also conceivable that active MMPs in the vitreous might facilitate remodelling events at the inner and outer limiting membranes of detached retina, leading to preretinal and subretinal proliferation, respectively. In a prospective study of PVR, Kon and co-workers demonstrated a significant association between vitreous levels of MMP-9 and the development of postoperative PVR. ${ }^{106}$ Work in our laboratory has also consistently demonstrated MMP-9 in retinectomy specimens from advanced cases of PVR (manuscript in preparation). ${ }^{107}$ This provides a mechanism for RPE cell dissociation from their basement membrane and migration through the retina.

Whether elevated MMP-9 is truly "pathogenic" in PVR, or merely a reflection of the underlying cellular activity, can only be answered by demonstrating inhibition of PVR 
induction in a physiological model with a strategy aimed at eliminating active MMP-9. There is some evidence to suggest that broad spectrum MMP inhibitors may prevent induction of experimental PVR ${ }^{108}$ and, as discussed above, such agents prevent induction of EAE. The mechanisms may not be dissimilar. The lesions in EAE contain inflammatory cells, activated glial cells, and macrophages which are also components of PVR membranes. Agents that prevent extravasation of inflammatory cells, transretinal migration of RPE cells and contraction of mesenchymal cells are thus rational choices for adjunctive therapy in PVR. Broad spectrum inhibitors might even have advantages over more selective therapy, as they will also protect the blood-retinal barrier by reducing release of proinflammatory TNF- $\alpha$ by cleavage at the cell surface. We propose that such therapy would best be instituted at an incipient or preclinical stage, to suppress the activation cascades that might evolve into PVR. This requires selecting patients at high risk of $\mathrm{PVR}^{106}$ and treating them at primary vitrectomy for retinal detachment, with a locally delivered MMP inhibitor. If a suitable long acting compound, or depot preparation, can be found, it is conceivable that, following a single application, induction of PVR could be suppressed until normal retinal homeostasis has been established. Current approaches to the pharmacological prevention of PVR have focused on nonspecific cellular proliferation inhibitors, such as 5-fluorouracil. ${ }^{109}$ It is possible that local MMP inhibition, introduced early enough, might form part of a targeted approach for PVR prevention, and perhaps to reduce recurrence following conventional PVR surgery.

\section{RETINAL NEOVASCULARISATION}

Retinal neovascularisation is an important cause of blindness, contributing to sight threatening complications associated with haemorrhage or retinal detachment in proliferative diabetic retinopathy (PDR), retinopathy of prematurity (ROP) and retinal vascular occlusions. Neoangiogenesis involves remodelling and proteolyis of the capillary basement membrane by migrating endothelial cells, which constitutively express mRNA for MMP-2, MMP-9, TIMP-1, and TIMP-2 in culture, ${ }^{110}$ enabling tight physiological control over this process. A well established model of retinal neovascularisation involves exposure of newborn mice to hyperoxia. ${ }^{11}$ This closely resembles ROP and has some features of PDR, such as capillary dropout and disc neovascularisation. Das and co-workers have demonstrated increases in active forms of retinal MMP-2 and MMP-9 by zymography, during the active phase of angiogenesis in this model. ${ }^{11} \mathrm{MMP}-2$ interacts with $\alpha_{\mathrm{v}} \beta_{3}$ integrin on endothelial cells to localise proteolytic activity, and it has been postulated that ECM fragments produced by local remodelling bind to further $\alpha_{v} \beta_{3}$ integrins to promote cell survival and matrix invasion. ${ }^{56}$ Such interactions might be disrupted by MMP inhibitors, and these authors document a reduction of neovascular nuclear counts by $72 \%$ in this model, with intraperitoneal administration of a synthetic MMP inhibitor. This suggests a pathogenic role for active gelatinases in the progression of neovascularisation. Further studies planned with topical applications at higher doses may have relevance for adjuvant treatment in patients undergoing vitreoretinal surgery for complications of established neovascularisation.

\section{Proliferative diabetic retinopathy}

Early histopathological features of diabetic retinopathy include basement membrane thickening, loss of pericytes, and microaneurysm formation. PDR supervenes when an initiating hypoxic stimulus drives expression of angiogenic proteins such as VEGF, and both hypoxia and VEGF can stimulate retinal capillary endothelial cells in culture to produce active MMP-2. ${ }^{12}$ Analysis of diabetic neovascular membranes and vitreous has produced interesting and somewhat contrasting results. In vitreous, proMMP-2 levels are similar between diabetic and non-diabetic subjects, whereas MMP-9 levels are significantly higher in diabetics, and correlate with disease progression, though most of the MMP-9 is in the latent form. ${ }^{113}$ The source of this proMMP-9 is unknown, but in the vitreous, at least, it seems to be more a marker of disease progression than actively involved in pathology. It may be produced in situ, reflect production by ischaemic retinal cells, or leak into the vitreous from new vessels. As in PVR, diabetic vitreous has significantly higher levels of TIMP-1 than found in non-proliferative vitreoretinal pathologies. ${ }^{97}$ This may contribute to maintaining vitreous MMPs in their latent form, limiting active proteolysis to sites of neovascularisation. At the tissue level, however, human diabetic neovascular membranes contain active forms of MMP-2 and MMP-9, ${ }^{114}$ demonstrated by zymography of extracted proteins. Sawicki and colleagues have reported that platelet derived MMP-2 is released during activation and mediates platelet aggregation and adhesion to the endothelium. ${ }^{15}$ This may be a generic process that proves to be a component of many vasculopathies, including PDR.

Clearly, MMP activity is critical for the cell-cell and cellmatrix interactions involved in capillary tube morphogenesis, so it represents a "final common pathway" in the process of retinal neovascularisation, from whatever cause. Inhibition at this level is thus potentially more attractive than targeting individual systems such as VEGF, as even if this could be effectively achieved, there may be some "escape" by other inducers of neovascularisation employing this final common pathway. Given the chronicity of diabetes, MMP inhibitors would have to be used long term to prevent or halt progression of PDR. This would require agents with long half lives, good bioavailability, and few side effects. To our knowledge, there are no clinical trials currently in progress for the use of MMP inhibitors to prevent PDR, but this could change if appropriate drugs were available and a case could be made for long term MMP inhibition reducing other complications of diabetes.

One consequence of hyperglycaemia is the irreversible, non-enzymatic glycosylation and oxidation of proteins to form advanced glycation end products (AGEs). These glucose derived cross links reduce collagen solubility and turnover and, it has been suggested, might affect MMP activation directly by protein modification, or indirectly, by their propensity to generate reactive oxygen intermediates, which can activate some proMMPs. ${ }^{116}$ The best characterised binding site for AGEs is a member of the immunoglobulin gene superfamily, referred to as Receptor for AGE, or "RAGE". Macrophages and other cells possess RAGEs that can ligate AGEs and stimulate the production of MMPs, adhesion molecules, and proinflammatory cytokines, such as TNF, IL-1, and IL-6, which can induce transcription of further matrix degrading enzymes.

Conventional glycaemic control is clearly important, and there is some experimental evidence that MMP inhibition may contribute to preventing hyperglycaemia. Subcutaneous administration of KB-R7785, a new MMP inhibitor, reduces plasma glucose levels in a rodent model of insulin resistance. This agent also inhibits a lipopolysaccharide induced increase in $\mathrm{TNF}-\alpha$ and may thus exert its anti-diabetic effect by ameliorating TNF- $\alpha$ mediated insulin resistance. ${ }^{117}$ The Diabetes Control and Complications Trial (DCCT) has shown that prolonged elevated serum glucose levels contribute to retinopathy and nephropathy. 
However, only $4 \%$ of subjects in the intensely treated cohort could maintain normal values for serum glucose and glycosylated haemaglobin. So, the majority of diabetics are exposed to elevated glucose concentrations during the course of their disease and developing strategies that can reduce long term complications independent of glycaemic status would considerably reduce morbidity.

Models of type I and type II diabetes in the rat demonstrate increased collagenase and gelatinase activity in skin and gingival extracts. ${ }^{116}$ Chemically modified tetracyclines (CMTs) are drugs that have lost their antimicrobial properties, but act as MMP inhibitors by influencing intracellular modulatory pathways through effects on a variety of cytokines, inducible nitric oxide synthase, cyclooxygenase, and AGE formation. CMT treatment in the rat diabetic models not only reduces elevated MMP levels, but also significantly reduces proteinuria, lens opacities, and prolongs survival.

Abnormal matrix turnover in mesangial cells has been postulated in the pathogenesis of diabetic nephropathy. ${ }^{118}$ Interestingly, plasma levels of MMP-9 increase before the development of microalbuminuria in non-insulin dependent diabetes and are significantly reduced after appropriate treatment with angiotensin converting enzyme inhibitors. ${ }^{119}$ Matrix components may also modulate the MMP activity of retinal microvascular cells in response to glucose, ${ }^{110}$ which may be important in the development of diabetic retinopathy. More detailed examination of experimental material will be required to establish the effect of CMT treatment on renal tissue and proliferative retinal disease, but these preclinical results are promising.

\section{UVEAL MELANOMA}

Uveal melanoma is a common primary intraocular neoplasm in adults with a 5 year survival rate of approximately $70 \%$. Metastasis is by haematogenous spread and there are several well established clinical markers of prognosis, including tumour size and location, cell type, patient age, and sex. ${ }^{120}$ MMPs and plasminogen activators have been shown to play a part in progression of cutaneous melanoma, which has a similar embryological origin. ${ }^{121}$ Evidence has recently emerged that MMP-2 may be a prognostic marker in uveal melanoma. An immunohistochemical study of 29 uveal melanomas by Vaisanen and colleagues demonstrated that positive immunostaining for MMP-2 in tumour cells correlated significantly with poorer 5 year relapse free and overall survival rates and a higher incidence of visceral metastases. ${ }^{122}$ Levels of MMP-2, TIMP-1, and TIMP-2 in the vitreous, where available for analysis, were not elevated compared with controls, and had no prognostic significance. Positive immunostaining for MMP-2 was demonstrated in the $\mathrm{RPE}$, photoreceptors, and fibroblasts of the ciliary body and choroid of enucleated eyes. The most significant difference in 5 year survival rates was between patients with MMP-2 positive non-spindle cell uveal melanoma (38\%) and MMP-2 negative spindle cell tumours (100\%).

However, these authors used a monoclonal antibody recognising a latent form of MMP-2. To determine whether MMP-2 is merely a marker of adverse outcome or actively involved in disease progression will require assessment of activation mechanisms and demonstration in tissue of active MMP-2, TIMP-2, and MT1-MMP. The cellular source of MMP-2 is uncertain and could be clarified by in situ hybridisation, which has demonstrated MMP-2 mRNA mainly in the stromal component of other tumours. ${ }^{123}$ Sequential activation and production of MMP-2 has been demonstrated during breast cancer progression ${ }^{124}$ and several lines of experimental evidence suggest that increased MMP-2 levels might have a causal role in an invasive phenotype. ${ }^{79}$ Exogenously added active gelatinases (MMP-2 and MMP-9) facilitate the in vitro invasion of a mammary tumour cell line. Transfection of the $\mathrm{C} 127$ breast cancer cell line with MMP-2 cDNA produces cells that metastasise to the lung when injected into the tail veins of nude mice. Importantly, there is a dose-response relation between the amount of active MMP-2 produced by the transfected cells in vitro and the number of lung nodules generated in vivo, and the administration of a synthetic gelatinase inhibitor prevents lung colonisation.

These observations suggest that gelatinase inhibition offers a strategy for preventing basement membrane destruction that accompanies cancer invasion. Several MMP inhibitors are presently in clinical trials for treatment of invasive malignant tumours, such as gastric, pancreatic, and ovarian carcinomas. ${ }^{30}$ As the results of such studies have implications for the management of ocular neoplastic invasion and metastasis, we will discuss the rationale behind this approach.

MMP inhibitors and the treatment of cancer

A "cure" for cancer through eradication of malignant cells has so far evaded us. The most effective alternative is to prolong survival through long term control of the disease. As an adjuvant treatment for malignancy, MMP inhibitors represent a fundamentally different approach to conventional cytoreductive therapy and may have a complementary role in treatment. Cytotoxic drugs target cells with a high proliferative index, but as these are also genetically unstable, adaptation can lead to treatment failure. However, tumours are composed not only of genetically altered neoplastic cells, but also genetically normal inflammatory, stromal, and endothelial cells, which are collectively required for manifestation of the malignant phenotype.

MMP inhibitors encourage the development of stromal fibrosis which inhibits tumour growth and invasion by promoting encapsulation. Necrosis of tumour tissue may be related to a subsequent increase in interstitial pressure or a direct anti-angiogenic effect of MMP inhibition. ${ }^{125} 126$ There is mounting evidence that MMP activity may play a part in the survival and growth of malignant cells. Tumours produced by injecting nude mice with ocular melanoma cells overexpressing TIMP-3 grow significantly more slowly than controls transfected with vector alone. ${ }^{127}$ Inhibition induced apoptosis ${ }^{123}$ may be contributing to a reduction of tumour burden, as well as a direct effect of MMP inhibition on tumour growth.

There are many excellent reviews on synthetic MMP inhibitors, to which the reader is referred for further information. ${ }^{85} 128$ The first generation of inhibitors were developed through structure based design to fit stereospecifically into the active site of MMPs. Broad spectrum peptide based MMP inhibitors such as batimastat suffer from poor oral bioavailability and have been used intraperitoneally for treatment of malignant ascites in ovarian cancer. Marimastat is water soluble and is "biologically active" given orally at $50 \mathrm{mg}$ twice daily. After 4 weeks of treatment, endoscopic examination of advanced gastric tumours demonstrated an increase in fibrotic stromal tissue. ${ }^{85}$ Randomised comparative trials are being conducted with marimastat in patients with pancreatic, lung, gastric, ovarian, and breast cancer. However, prolonged treatment is associated with arthralgia, directing research towards more selective inhibitors. More selective targeting of MMPs may be preferable in cancer treatment, as MMP-3, MMP-7, MMP-9, and MMP-12 can generate angiostatin from plasminogen, and may thus suppress tumour growth by limiting angiogenesis. Trials are thus 
under way with gelatinase "selective" compounds such as AG3340 and BAY 12-9566.

Combination treatments with conventional cytotoxic chemotherapies are also under evaluation in cancer patients and animal models, with some indication that an additive effect can be achieved. We have already referred to CMTs acting as broad spectrum MMP inhibitors, independent of their antimicrobial effects. They can also induce apoptosis of malignant cells and have more favourable pharmacokinetics and tissue absorption than conventional MMP inhibitors, with well recognised safety profiles for long term management. They may prove useful in the adjuvant treatment of malignancy and have been effective in reducing metastases in a rat model of prostatic carcinoma. ${ }^{129}$ The real test for MMP inhibitors will be whether they can increase overall survival in the adjuvant treatment of micro-metastatic disease, once clinical trials move beyond the treatment of advanced pathology.

HEREDITARY AND DEGENERATIVE DISEASES

TIMP-3 is a protein of approximately $24 \mathrm{kDa}$, whose main physiological function is probably to control ECM remodelling via regulation of MMPs. It is distinct from other TIMPs in being an insoluble component of the $\mathrm{ECM}^{9}$ and is demonstrated in Bruch's membrane by immunohistochemistry ${ }^{130}$, with in situ hybridisation locating production to the RPE and choroid. ${ }^{131}$ TIMP-3 has anti-angiogenic activity, demonstrated by reduced chemotaxis of vascular endothelial cells towards growth factors such as vascular endothelial growth factor in the presence of TIMP-3. ${ }^{132}$ Ophthalmology has led the search for genetically determined causes of abnormal matrix turnover by extensive study of the TIMP-3 gene in Sorsby's fundus dystrophy, discussed below. Polymorphisms in the other TIMP genes are now being discovered in individuals with connective tissue remodelling dysfunction leading to aneurysmal dilatation. ${ }^{133}$

\section{Sorsby's fundus dystrophy}

Sorsby's fundus dystrophy (SFD) is an autosomal dominant inherited macular dystrophy first described by Sorsby in $1949 .{ }^{134}$ Central visual loss occurs secondary to geographic atrophy and choroidal neovascularisation in the fifth decade of life, and this is accompanied by a thickening of Bruch's membrane. ${ }^{135}$ The disease links to chromosome 22 q13ter, and is associated with mutations in exon 5 of the TIMP-3 gene. ${ }^{136}$

One common mutation of TIMP-3 has been identified in SFD within the UK, although four others have also been described elsewhere in the world. ${ }^{136-139}$ As the normal function of TIMP-3 is to control ECM remodelling and inhibit angiogenesis, the link between mutation and the SFD phenotype is clear, though we have yet to characterise exactly how mutant TIMP-3 is compromised in these functions. The mutations reported so far all result in the incorporation of an additional cysteine residue, which allows the possibility of inappropriate disulphide bridge formation that could affect structure and stability of the mature protein. Indeed, when the mutant form of TIMP-3 was introduced into an expression system, a $48 \mathrm{kDa}$ species was produced, suggestive of a dimer. This might be more difficult to degrade and could accumulate within Bruch's membrane. ${ }^{139}$ The mutant form retained some ability to inhibit MMPs and localise to the $\mathrm{ECM}^{140}$ suggesting that SFD may result from a subtle alteration in activity or turnover, rather than loss of function.

Anande-Apte and co-workers have suggested that, being a dominant disease, half the TIMP-3 in SFD will be the mutant form, so the phenotype may arise from haploinsufficiency or through an interference effect of the mutant protein. ${ }^{127}$ If SFD were merely a consequence of half the functional protein being produced, we might expect net proteolytic activity to increase, resulting in a thinned Bruch's membrane. Histology of SFD eyes, however, has revealed irregular thickening of Bruch's membrane, strongly immunopositive for TIMP-3, except where there is associated RPE degeneration, suggesting a role for the RPE in TIMP-3 turnover. ${ }^{141}$ The sub-RPE deposits may be interfering with nutritonal support of the RPE and photoreceptors, leading to their degeneration. Other organs are unaffected, emphasising the exquisitely sensitive control of matrix turnover in the posterior segment of the eye. The abnormal material may represent mutant TIMP-3 that is resistant to turnover, or binding of TIMP-3 to abnormal matrix accumulations. Presently, antibodies do not distinguish between normal and mutant TIMP-3, so such questions remain unanswered. Work has intensified on transgenic models and in vitro systems to understand the function and turnover of mutant TIMP-3. Understanding SFD may provide insights to the pathogenesis of age related macular degeneration, which it resembles in several respects.

\section{Age related macular degeneration}

Age related macular degeneration (AMD) is the leading cause of blindness in the developed world, and its prevalence is increasing. ${ }^{142}$ The disease may be broadly classified into exudative or non-exudative types according to the presence or absence of choroidal neovascularisation. Exudative AMD accounts for only about $10 \%$ of cases, but has a worse visual prognosis. ${ }^{143}$

Despite differences in age of onset, the clinical manifestations of exudative AMD and Sorsby's fundus dystrophy show several similarities, including choroidal neovascularisation and thickening of the Bruch's membrane. The observation of these similarities has therefore led to the investigation of the TIMP-3 locus in AMD. However, analysis of this gene in AMD and other macular dystrophies failed to identify mutations in diseases other than SFD, ${ }^{144}$ as did linkage analysis of AMD families in the USA. ${ }^{145}$ Bruch's membrane thickening is a characteristic of $\mathrm{AMD}$, and accumulation of TIMP-3 in this layer has been shown by immunohistochemistry. ${ }^{130}{ }^{139}$ Western blotting and quantitative reverse zymography have been used to demonstrate an age related increase in normal donor eyes. ${ }^{146}$ Moreover, single and continuous drusen deposits in AMD are highly reactive with TIMP-3 antibodies, as are sub-RPE deposits found in a dominant form of retinitis pigmentosa, also lacking any TIMP-3 mutation. Here, they have been demonstrated to occlude lumina of retinal vessels, contributing to hypoxic neuroretinal degeneration. ${ }^{141}$ In these conditions, TIMP-3 may be accumulating by binding to abnormal constituents of Bruch's membrane.

While the TIMP-3 gene is normal in AMD, there remains the possibility that defective gene regulation may be responsible for the ocular phenotype, and understanding such regulatory mechanisms may be just as important as identifying candidate genes in AMD. In $\mathrm{X}$ linked progressive retinal atrophy, a canine model of $\mathrm{X}$ linked retinitis pigmentosa (XLRP), TIMP-1 has been excluded as a candidate gene, despite being in close proximity to one of the two XLRP loci, and overexpression of TIMP-1 months before histologically evident retinal degeneration. ${ }^{147}$ If subtle changes in matrix turnover could be identified-for example, by serial measurements of Bruch's membrane thickness using a modality such as high resolution optical coherence tomography, ${ }^{148}$ we might, in the future, be able to identify patients at risk of AMD before the pathological sequelae are too advanced. 
A rational approach to therapy would entail first identifying the matrix components that are responsible for the histopathological changes in Bruch's membrane and then establishing which MMP(s) might mediate effective turnover of these components. Quantitative analyses of the effect of ageing on the MMP content of human retina, Bruch's membrane, or choroid are difficult to interpret, owing to variation in technique and postmortem fixation time, which might influence enzyme degradation or diffusion out of the relevant compartment. The source of MMPs and TIMPs in Bruch's membrane is likely to be the RPE. Authors have described increases in MMP-2 in RPE associated interphotoreceptor matrix in $\mathrm{AMD},{ }^{149}$ and increases in MMP-2 and MMP-9 with age in isolated human Bruch's-choroid complex. ${ }^{150}$ In both cases, the enzymes were almost entirely inactive forms, and attributing a direct pathogenic role for these findings in AMD is thus oversimplistic. Accumulation of inactive MMPs is more likely to be a consequence of Bruch's membrane remodelling than causal. Increased deposition of collagen and other ECM components may provide a signal for increased MMP synthesis. Appropriate remodelling fails, however, as the enzymes are not activated. This may be due to the increased concentration of TIMP-3 present, or to decreased porosity of Bruch's membrane from increased collagen cross linking, denying access to legitimate MMP activators. This would also limit access of MMPs to appropriate substrates and hence cause further ECM accumulation. Subsequent zymogen turnover might be slower, contributing to the observed increase with age.

An intriguing question is whether activation of these enzymes precedes or contributes to neovascularisation. The answer might lie in studying large numbers of Bruch's membrane isolates from donor eyes with a spectrum of pathology covering "dry", "wet", early, and advanced forms of AMD. Treatment of AMD by modulating the MMP axis is thus fraught with difficulty. It may be that, in the dry form of the disease, MMP activation or supplementation would be beneficial. Presumably, tissue specific upregulation of MMP production by the RPE could only be achieved by subretinal gene therapy, or by direct introduction of the relevent enzyme(s) or activator(s), both involving extensive surgery. ${ }^{151}$ Perhaps there are less invasive alternatives for enhancing proteolytic activity in Bruch's membrane, such as laser stimulation, which we know can promote clearance of drusen and improve visual acuity and contrast sensitivity. ${ }^{152}$ Even if these issues are addressed, there are many unanswered questions. Would "proteolytic housekeeping" of Bruch's membrane be a one off treatment, or would more frequent "spring cleaning proteolysis" be required to maintain a healthy ECM? Once the disease has progressed to an exudative stage, MMP inhibition might be the appropriate strategy to suppress neovascularisation. That we can even postulate such strategies does offer some hope for patients, and their ophthalmologists, though there are major, unresolved issues regarding when to offer treatment in the natural history of the disease and the relative merits and efficacy of local versus systemic treatment.

\section{CHOROIDAL NEOVASCULARISATION}

Subfoveal choroidal neovascularisation is an important cause of visual loss in patients with age related macular degeneration, ocular histoplasmosis syndrome, and other disorders characterised by defects in Bruch's membrane. ${ }^{153154}$ Surgical excision of neovascular membranes is under evaluation as a potential treatment and has provided tissue specimens to study pathogenesis. Steen et al recently reported the results of analysis for MMP and TIMP mRNA by in situ hybridisaton in surgically excised membranes. ${ }^{155}$ Localisation of MMP-2 and MMP-9 expression to areas of new vessel formation and Bruch'slike membrane, suggests a possible role for these gelatinases in the growth of neovascular complexes. MMP-7 has been implicated in tumour progression ${ }^{156}$ and has also recently been demonstrated in Bruch's membrane-like material around RPE cells in CNV membranes. ${ }^{157}$ Inhibition of MMP activity might not be an effective treatment for established CNV complexes, but could conceivably prevent their development and growth, or reduce recurrence after laser photocoagulation or surgical excision.

A phase II clinical trial is currently being undertaken in the United States to assess an oral MMP inhibitor (AG3340) for treatment of subfoveal CNV secondary to AMD. ${ }^{158}$ This agent is a potent, non-peptidic MMP inhibitor with selectivity for a subclass of MMPs involved in angiogenesis, including the gelatinases MMP-2 and MMP-9, and MT1-MMP. AG3340 is also currently undergoing advanced oncology clinical trials ${ }^{159}$ and can inhibit cellular proliferation and induce apoptosis in tumours. It has been shown to decrease angiogenesis by approximately $50 \%$ in a variety of tumour models, on twice daily oral dosing, and by $77 \%$ after once daily intraperitoneal dosing in a newborn mouse model of retinal neovascularisation. ${ }^{160}$ Plasma concentrations associated with preclinical efficacy in tumour models are readily achieved with twice daily oral dosing in human subjects. ${ }^{161}$ Sparing of $\mathrm{MMP}-1$ may reduce adverse effects such as arthralgia, as MMP-1 is found in normal joints, but the potential systemic toxicity of AG3340 calls for caution when its use is proposed for a non-life threatening ophthalmic condition. The oncology trials will, however, provide useful data on the safety and tolerance of long term therapy, as prevention of CNV recurrence may require chronic treatment. An interesting evolution of such work would involve high dose, tissue specific application of a related derivative following surgical excision of CNVs, perhaps followed by maintenance on a lower oral dose. For this to be efficacious in AMD, however, the major issues of pigment epithelial loss and photoreceptor degeneration will need to be addressed.

\section{Future directions}

MMP research is an exciting and rapidly evolving field, covering a variety of disease related processes in a number of medical and surgical disciplines. Improvements in antibody specificity will enable us to reliably differentiate between active and latent forms in tissues, which might assist diagnosis and contribute to prognostic information, as well as suggest targets for therapy. New techniques such as cDNA microarray analysis will enable us to profile, and ultimately quantify, multiple gene expression in small specimens. ${ }^{162}$ Such an approach is likely to be instructive in the complex vitreoretinal disorders discussed above, where multiple MMPs may be participating in pathology, and where net proteolytic activity is dependent on a balance between MMP and TIMP expression. Novel disease related genes have already been discovered in anterior segment disorders, using this methodology. ${ }^{163}$

The posterior segment of the eye presents potential problems regarding the biological activity of agents in relevant compartments following systemic treatment. Local drug or vector delivery is, however, possible with a degree of precision that may not be possible in other organs. Where conventional treatment has been surgical, such as in PVR, adjuvant strategies to manipulate the MMP axis can be assessed, once issues of safety and specificity have been resolved. Treatment of "medical" retinal disorders may follow, once we understand more completely the control of expression and activation of MMPs and TIMPs. 
Chemical inhibitors currently being evaluated in trials are relatively non-specific, but as MMP structure-function relations continue to be teased apart, more specific inhibitors will emerge for individual MMPs or subclasses, based on $x$ ray crystallography of active enzyme sites. ${ }^{128}$ Protease activatable gene delivery vehicles to target cells overexpressing MMPs in disease are currently in development. ${ }^{164}$ The important role of MMPs in normal physiological processes suggests that inhibition should ideally be targeted to diseased tissues, which remains a challenge. Perhaps targeting "inducible" regions of MMP genes would selectively protect "constitutive" expression and thus not interfere significantly with physiological processes.

Molecular strategies for manipulating the MMP axis will also be developed, as every level of regulation of MMP expression and activity is a potential target for therapeutic intervention. Inhibition might be achieved by targeting messenger RNA production with antisense oligonucleotides or ribozymes ${ }^{165}$ and improvements in transfection technology would enable TIMP overexpression in selected cells. It is also possible that selective chemical inhibitors for distinct signalling pathways, such as mitogen activated protein kinase (MAPK) and protein kinase C (PKC), may soon be available for clinical trials. This would provide a novel strategy for reducing MMP expression by inhibiting MMP promotor activation. ${ }^{124}$ Retinoids and tetracyclines are among compounds being explored for this purpose. ${ }^{166}$

Such directed research will facilitate studies on the specific role of individual MMPs in biological processes involving matrix turnover. We will see potential therapies tested in new models of disease, and advances in transgenic technology ${ }^{167}$ will provide opportunities to perform controlled experiments in complex biological systems. Finally, while we continue to tackle established vitreoretinal pathologies in the new millennium, matrix biology will be contributing significantly to our fundamental understanding of ocular developmental and homeostatic processes.

CSS is a Medical Research Council clinical training fellow and TAB is supported by the Royal College of Surgeons of Edinburgh research grant.

C S SETHI

Department of Pathology, Institute of Ophthalmology, and

Moorfields Eye Hospital, London

T A BAILEY

P J LUTHERT

Department of Pathology, Institute of Ophthalmology, London N H V CHONG

Department of Pathology, Institute of Ophthalmology, and Moorfields Eye Hospital, London

Correspondence to: Mr C S Sethi, Vitreoretinal Surgery, Moorfields Eye Hospital, City Road, London EC1V 2PD

1 Matrisian LM. Metalloproteinases and their inhibitors in matrix remodeling. Trends Genet 1990;6:121-5.

2 Shapiro SD. Matrix metalloproteinase degradation of extracellular matrix: Shapiro SD. Matrix metalloproteinase degradation of extracell
biological consequences. Curr Opin Cell Biol 1998;10:602-8.

3 Moses MA, Marikovsky M, Harper JW, et al. Temporal study of the activity of matrix metalloproteinases and their endogenous inhibitors during of matrix metalloproteinases and their endogen
wound healing. $\mathcal{F}$ Cell Biochem 1996;60:379-86.

4 Bramhall SR. The matrix metalloproteinases and their inhibitors in pancreatic cancer. Int $\mathcal{F}$ Pancreatol 1997;21:1-12.

5 Brown PD. Matrix metalloproteinase inhibitors in the treatment of cancer. Med Oncol 1997;14:1-10

6 Rasmussen HS, McCann PP. Matrix metalloproteinase inhibition as a novel anticancer strategy: a review with special focus on batimastat and marimastat. Pharmacol Ther 1997;75:69-75.

7 Brown PD. Clinical studies with matrix metalloproteinase inhibitors. APMIS 1999;107:174-80.

8 Pilcher BK, Wang M, Qin X-J, et al. Role of matrix metalloproteinases and their inhibition in cutaneous wound healing and allergic contact hypersensitivity. Ann NY Acad Sci 1999;878:12-24.

9 Gomez DE, Alonso DF, Yoshiji H, et al. Tissue inhibitors of metalloproteinases: structure, regulation and biological functions. Eur $\mathcal{F}$ metalloproteinases: structure,
Cell Biol 1997;74:111-22.

10 Cawston TE, Billington C. Metalloproteinases in the rheumatic diseases. $\mathcal{F}$ Pathol 1996;180:115-7.
11 Murphy G, Docherty AJP, Hembry RM, et al. Metalloproteinases and tissue damage. Br 7 Rheumatol 1991;30(suppl 1): 25-31.

12 Kahari VM, Saarialho-Kere U. Matrix metalloproteinases in skin. Exp Dermatol 1997;6:199-213.

13 Sorsa T, Mantyla P, Ronka H, et al. Scientific basis of a matrix metalloproteinase-8 specific chair-side test for monitoring periodontal and peri-implant health and disease. Ann NY Acad Sci 1999;878:130-49.

14 Vaalamo M, Weckroth M, Puolakkainen P, et al. Patterns of matrix metalloproteinase and TIMP-1 expression in chronic and normally healing human cutaneous wounds. Br F Dermatol 1996;135:52-9.

15 Nwomeh BC, Liang HX, Cohen IK, et al. MMP-8 is the predominant collagenase in healing wounds and non-healing ulcers. 7 Surg Res 1999;81:189-95.

16 Kossakowska AE, Edwards DR, Lee SS, et al. Altered balance between matrix metalloproteinases and their inhibitors in experimental biliary fibrosis. Am f Pathol 1998;153:1895-902

17 Fukuda Y, Ishizaki M, Kudoh S, et al. Localisation of matrix metalloproteinases-1,-2 and -9and tissue inhibitor of metalloproteinase-2 in interstitial lung diseases. Lab Invest 1998;78:687-98.

18 Matila L, Airola K, Ahonen M, et al. Activation of TIMP-3 mRNA expression in scleroderma skin fibroblasts. F Invest Dermatol 1998;110:416-21.

19 Murate T, Yamashita K, Isogai C, et al. The production of TIMPs in megakaryopoesis: possible role of platelet- and megakaryocyte-derived TIMPs in bone marrow fibrosis. Br f Haematol 1997;99:181-9.

20 Hembry RM, Ehrlich HP. Immunolocalisation of collagenases and TIMPs in hypertrophic scar tissue. Br f Dermatol 1986;115:409-20.

21 Massova I, Kotra LP, Fridman R, et al. Matrix metalloproteinases: structures, evolution and diversification. FASEB 7 1998;12:1075-95.

22 Baramova E, Foidart J-M. Matrix metalloproteinase family. Cell Biol Int 1995;19:239-42.

23 Kleiner DE, Stetler-Stevenson WG. Structural biochemistry and activation of matrix metalloproteinases. Curr Opin Cell Biol 1993;5:891-7.

24 Murphy G, Knauper V. Relating matrix metalloproteinase structure to function: why the 'hemopexin' domain? Matrix Biol 1997;15:511-8.

25 Seiki M. Membrane-type matrix metalloproteinases. APMIS 1999;107:13743.

26 Pei D. Identification and characterisation of the fifth membrane-type matrix metalloproteinase MT5-MMP. F Biol Chem 1999;274:8925-32.

27 Murphy G, Knauper V, Cowell S, et al. Evaluation of some newer matrix metalloproteinases. Ann NY Acad Sci 1999;878:25-39.

28 Crawford HC, Matrisian LM. Mechanisms controlling the transcription of matrix metalloproteinase genes in normal and neoplastic cells. Enzyme Protein 1996;49:20-37.

29 Murphy G. The regulation of connective tissue metalloproteinases by natural inhibitors. Agents Actions 1991; (suppl) 35:69-76.

30 Kahari VM, Saarialho-Kere U. Matrix metalloproteinase and their inhibitors in tumour growth and invasion. Ann Med 1999;31:34-45.

31 Bond M, Fabunmi RP, Baker AH, et al. Synergistic upregulation of metalloproteinase-9 by growth factors and inflammatory cytokines: an absolute requirement for transcription factor NF-kappa B. FEBS Lett

2 Murphy G, Ward R, Gavrilovic J, et al. Physiological mechanisms for metalloproteinase activation. Matrix 1992; suppl 1:224-230.

33 Hiraoka N, Allen E, Apel IJ, et al. Matrix metalloproteinases regulate neovascularisation by acting as pericellular fibrinolysins. Cell 1998;95:365-

34 Gomis-Ruth F-X, Maskos K, Betz M, et al. Mechanism of inhibition of the human matrix metalloproteinase stromelysin-1 by TIMP-1. Nature 1997;389:77-81

35 Fortunato SJ, Menon R, Lombardi SJ. Presence of four tissue inhibitors of metalloproteinases (TIMP-1, $-2,-3$ and -4) in human fetal membranes. Am F Reprod Immunol 1998;40:395-400.

36 Li YY, McTiernan CF, Feldman AM. Proinflammatory cytokines regulate tissue inhibitors of metalloproteinases and disintegrin metalloproteinase in cardiac cells. Cardiovasc Res 1999;42:162-72.

37 Overall CM. Regulation of tissue inhibitor of matrix metalloproteinase expression. Ann NY Acad Sci 1994;732:51-64.

38 Leco KJ, Khokha R, Pavloff $\mathrm{N}$, et al. TIMP-3 is an extracellular matrix-associated protein with a distinctive pattern of expression in mouse matrix-associated protein with a distinctive pattern
cells and tissues. $\mathcal{7}$ Biol Chem 1994;269:9352-60.

39 Hayakawa T, Yamashita K, Ohuchi E, et al. Cell growth-promoting activity of tissue inhibitor of metalloproteinse-2 (TIMP-2). F Cell Sci 1994;107: $2373-9$

40 Hayakawa T, Yamashita K, Tanzawa E, et al. Growth-promoting activity of tissue inhibitor of metalloproteinase-1 (TIMP-1) for a wide range of cells. FEBS Lett 1992;298:29-32.

41 Sang QX. Complex role of matrix metalloproteinases in angiogenesis. Cell Res 1998;8:171-7.

42 Anderson K, Maelandsmo GM, Hovig E, et al. Interleukin-1 alpha and basic fibroblast growth factor induction of matrix metalloproteinases and their inhibitors in osteosarcoma cells is modulated by the metastasis associated protein CAPL. Anticancer Res 1998;18:3299-303.

43 Schonbeck U, Mach F, Libby P. Generation of biologically active IL-1 beta by matrix metalloproteinases: a novel caspase-1 independent pathway of by matrix metalloproteinases: a novel caspase-1 ind

44 Zhang Y, McCluskey K, Fujii K, et al. Differential regulation of monocyte matrix metalloproteinase and TIMP-1 production by TNF-alpha, granulocyte-macrophage CSF and IL-1 beta through prostaglandindependent and -independent mechanisms. F Immunol 1998;161:3071-6.

45 Johnatty RN, Taub DD, Reeder SP, et al. Cytokine and chemokine regulation of pro-MMP-9and TIMP-1 production by human peripheral blood lymphocytes. F Immunol 1997;158:2327-33.

46 Matrisian LM, Ganser GL, Kerr LD, et al. Negative regulation of gene expression by TGF-beta. Mol Reprod Dev 1992;32:111-20.

47 Edwards DR, Murphy G, Reynolds JJ, et al. Transforming growth factor beta modulates the expression of collagenase and metalloproteinase inhibitor. EMBO f 1987;6:1899-904

48 Ignotz RA, Massague J. Transforming growth factor-beta stimulates the expression of fibronectin and collagen and their incorporation into the extracellular matrix. F Biol Chem 1986;261:4337-45.

49 Connor TB, Roberts AB, Sporn MB, et al. Correlation of fibrosis and transforming growth factor- $\beta$ type 2 levels in the eye. $\mathcal{f}$ Clin Invest 1989;83:1661-6. 
50 Imai K, Hiramatsu A, Fukushima D, et al. Degradation of decorin by matrix metalloproteinase: identification of the cleavage sites, kinetic analyses and transforming growth factor-beta1 release. Biochem f 1997;322:809-14

51 Rifkin DB, Mazzieri R, Munger JS, et al. Proteolytic control of growth factor availability. APMIS 1999;107:80-5

$52 \mathrm{McGeehan} \mathrm{GM,} \mathrm{Becherer} \mathrm{JD,} \mathrm{Bast} \mathrm{RC,} \mathrm{et} \mathrm{al.} \mathrm{Regulation} \mathrm{of} \mathrm{tumour} \mathrm{necrosis}$ factor- $\alpha$ processing by a metalloproteinase inhibitor. Nature 1994;370:55861.

53 Levi E, Fridman R, Miao HQ, et al. Matrix metalloproteinase-2 releases active soluble ectodomain of fibroblast growth factor receptor-1. Proc Natl Acad Sci USA 1996;93:7069-74.

54 Moss ML, Jin S-LC, Milla ME, et al. Cloning of a disintegrin metalloproteinase that processes precursor tumour necrosis factor- $\alpha$. Nature $1997 ; 385$ : 733-6.

55 Black RA, Rauch CT, Kozlosky CJ, et al. A metalloproteinase disintegrin that releases tumour necrosis factor- $\alpha$ from cells. Nature 1997;385:729-33.

56 Murphy G, Gavrilovic J. Proteolysis and cell migration: creating a path? Curr Opin Cell Biol 1999;11:614-621.

57 Streuli C. Extracellular matrix remodeling and cellular differentiation. Curr Opin Cell Biol 1999;11:634-40.

58 Fowlkes JL, Serra DM, Nagase $\mathrm{H}$, et al. MMPs are IGFBP-degrading proteinases: implication for cell proliferation and tissue growth. Ann NY Acad Sci 1999;878:696-9.

59 Kieseier BC, Seifert T, Giovannoni G, et al. Matrix metalloproteinases in inflammatory demyelination. Neurology 1999;53:20-5.

60 Mun-Bryce S, Rosenberg GA. Gelatinase B modulates selective opening of the blood-brain barrier during inflammation. Am f Physiol 1998;274: R1203-11.

61 Stuve O, Dooley NP, Uhm JH, et al. Interferon beta-1b decreases the migration of T lymphocytes in vitro: effects on matrix metalloproteinase-9. Ann Neurol 1996;40:853-63.

62 Shapiro SD, Campbell EJ, Kobayashi DK, et al. Immune modulation of metalloproteinase production in human macrophages. $f$ Clin Invest 1990;86:1204-10.

63 Ashley RA and the SDD Clinical Research Team. Clinical trials of a matrix metalloproteinase inhibitor in human periodontal disease. Ann NY Acad Sci 1999;878:335-46.

64 Zucker S, Hymowitz M, Connor C, et al. Measurement of matrix metalloproteinases and tissue inhibitors of metalloproteinases in blood and metalloproteinases and tissue inhibitors of m
tissues. Ann NY Acad Sci 1999;878:212-27.

65 Lein M, Nowak L, Jung K, et al. Analytical aspects regarding the measurement of metalloproteinases and their inhibitors in blood. Clin Biochem 1997;30:491-6.

66 Kanbe N, Tanaka A, Kanabe M, et al. Human mast cells produce matrix metalloproteinase-9. Eur f Immunol 1999;29:2645-9.

67 Arumugam S, Jang Y-C, Chen-Jensen C, et al. Temporal activity of plasminogen activators and matrix metalloproteinases during cutaneous wound repair. Surgery 1999;125:587-93.

68 Salo T, Makela M, Kylmaniemi M, et al. Expression of matrix metalloproteinase-2 and -9 during early human wound healing. Lab Invest 1994;70:176-82.

69 Di Colandrea T, Wang L, Wille J, et al. Epidermal expression of collagenase delays wound healing in transgenic mice. F Invest Dermatol 1998;111:102933.

70 Vaalaom M, Leivo T, Saarialho-Kere U. Differential expression of tissue inhibitors of metalloproteinases (TIMP-1,-2,-3 and -4 ) in normal and aberrant wound healing. Hum Pathol 1999;30:795-802.

71 Kawashima Y, Saika S, Yamanaka O, et al. Immunolocalisation of matrix metalloproteinases and tissue inhibitors of metalloproteinases in human subconjunctival tissues. Curr Eye Res 1998;17:445-51.

72 Kumar R, Yoneda J, Bucana CD, et al. Regulation of distinct steps of angiogenesis by different angiogenic molecules. Int $\mathcal{F}$ Oncol 1998;12:749-57.

73 Moses MA. The regulation of neovascularisation by matrix metalloproteinases and their inhibitors. Stem Cells 1997;15:180-9.

74 Murphy AN, Unsworth EJ, Stetler-Stevenson WG, et al. Tissue inhibitor of metalloproteinases-2 inhibits bFGF-induced human microvascular endothelial cell proliferation. 7 Cell Physiol 1993;157:351-8.

75 Clark AF. New discoveries on the roles of matrix metalloproteinases in ocular cell biology and pathology. Invest Ophthalmol Vis Sci 1998;39:2514-6.

76 Brooks PC, Silletti S, von Schalscha TL, et al. Disruption of angiogenesis by PEX, a non-catalytic metalloproteinase fragment with integrin binding activity. Cell 1998;92:391-400.

77 Unemori EN, Ferrara N, Baurer EA, et al. Vascular endothelial growth factor induces interstitial collagenase expression in human endothelial cells. $\mathcal{F}$ Cell Physiol 1991;153:557-62.

78 Garzetti GG, Ciavattini A, Lucarini G, et al. Expression of vascular endothelial growth factor related to 72 -kilodalton immunostaining in patients with serous ovarian tumours. Cancer 1999;85:2219-25.

79 Cockett MI, Murphy G, Birch ML, et al. Matrix metalloproteinases and metastatic cancer. Biochem Soc Symp 1998;63:295-313.

80 Zucker S. Experimental models to identify antimetastatic drugs: are we there yet? Ann NY Acad Sci 1999;878:208-11.

81 Fingleton $\mathrm{BM}$, Goss $\mathrm{KJH}$, Crawford $\mathrm{HC}$, et al. Matrilysin in early stage intestinal tumorigenesis. APMIS 1999;107:102-10.

82 Ring $\mathrm{P}$, Johansson $\mathrm{K}$, Hoyhtya $\mathrm{M}$, et al. Expression of tissue inhibitor of metalloproteinases TIMP-2 in human colorectal cancer-a predictor of metalloproteinases TIMP-2 in human color
tumour stage. Br $\mathcal{F}$ Cancer 1997;76:805-11.

83 Ahmad A, Hanby A, Dublin E, et al. Stromelysin-3: an independent prognostic factor for relapse-free survival in node-positive breast cancer and demonstration of novel breast carcinoma cell expression. Am f Pathol 1997; 152:721-8.

84 Vaisanen A, Killioinen M, Taskinen PJ, et al. Prognostic value of MMP-2 immunoreactive protein $(72 \mathrm{kD}$ type IV collagenase) in primary skin melanoma. F Pathol 1998;186:51-8.

85 Brown PD. Matrix metalloproteinase inhibitors. Breast Cancer Res Treat 1998;52:125-36.

86 Henriet P, Blavier L and Declerck YA. Tissue inhibitors of metalloproteinases (TIMP) in invasion and proliferation. APMIS 1999;107:111-9.

87 Blavier L, Henriet P, Imren S, et al. Tissue inhibitors of matrix metalloproteinases in cancer. Ann NY Acad Sci 1999;878:108-19.

88 DeClerck YA, Perez N, Shimada H, et al. Inhibition of invasion and metastasis in cells transfected with an inhibitor of metalloproteinases. Cancer Res 1992;52:701-8.
89 Kruger A, Sanchez-Sweatman OH, Martin DC, et al. Host TIMP-1 overexpression confers resistance to experimental brain metastasis of a pression confers resistance to experimental b

90 Bramhall SR, Neoptolemos JP, Stamp GW, et al. Imbalance of expression of matrix metalloproteinases (MMPs) and tissue inhibitors of the matrix metalloproteinases (TIMPs) in human pancreatic carcinoma. $f$ Pathol 1997;182:347-55.

91 Plantner JJ, Smine A, Qhinn TA. Matrix metalloproteinases and metalloproteinase inhibitors in human interphotoreceptor matrix and vitreous. Curr Eye Res 1998;17:132-40.

92 Padgett LC, Lui GM, Werb Z, et al. Matrix metalloproteinase-2 and tissue inhibitor of metalloproteinase-1 in the retinal pigment epithelium and
interphotoreceptor matrix: vectorial secretion and regulation. Exp Eye Res 1997;64:927-38.

93 Smine A, Plantner JJ. Membrane type-1 matrix metalloproteinase in human ocular tissues. Curr Eye Res 1997;16:925-9.

94 Charteris DG. Proliferative vitreoretinopathy: pathobiology, surgical management, and adjunctive treatment. Br f Ophthalmol 1995;79:953-60.

95 Scott KA, Wood EJ, Karran EH. A matrix metalloproteinase inhibitor which prevents fibroblast-mediated collagen lattice contraction. FEBS Lett 1998; 441:137-40.

96 Immonen I, Konttinen YT, Sorsa T, et al. Proteinases in subretinal fluid. Graefes Arch Clin Exp Ophthalmol 1996;234:105-9.

97 Matsuo T, Okada Y, Shiraga F, et al. TIMP-1 and TIMP-2 levels in vitreous and subretinal fluid. Fpn $\mathcal{F}$ Ophthalmol 1998;42:377-80.

98 De La Paz MA, Itoh Y, Toth CA, et al. Matrix metalloproteinases and their inhibitors in human vitreous. Invest Ophthalmol Vis Sci 1998;39:1256-60.

99 Alexander JP, Bradley JMB, Gabourel JD, et al. Expression of matrix metalloproteinases and inhibitor by human retinal pigment epithelium. Invest Ophthalmol Vis Sci 1990;31:2520-8.

100 Kosnosky W, Li TH, Pakalnis VA, et al. Interleukin-1- $\beta$ changes the expression of metalloproteinases in the vitreous humor and induces membrane formation in eyes with pre-existing retinal holes. Invest Ophthalmol Vis Sci 1994;35:4260-7.

101 Hunt RC, Fox A, Pakalnis VA, et al. Cytokines cause cultured retinal pigment epithelial cells to secrete metalloproteinases and to contract collagen gels. Invest Ophthalmol Vis Sci 1993;34:3179-86.

102 Webster L, Chignell AH, Limb GA. Predominance of MMP-1 and MMP-2 in epiretinal and subretinal membranes of proliferative vitreoretinopathy. Exp Eye Res 1999;68:91-8.

103 Kolb SA, Lahrtz F, Paul R, et al. Matrix metalloproteinases and tissue inhibitors of metalloproteinases in viral meningitis: upregulation of 50 .

104 Norman JT, Clark IM, Garcia PL. Regulation of TIMP-1 expression by hypoxia in kidney fibroblasts. Ann NY Acad Sci 1999;878:503

105 Limb GA, Miller K, Chignell AH, et al. Metalloproteinases and TIMP-1 in proliferative vitreoretinopathy. Biochem Soc Trans 1997;25:234S.

106 Kon CH, Occleston NL, Charteris DG, et al. A prospective study of matrix metalloproteinases in proliferative vitreoretinopathy. Invest Ophthalmol Vis Sci 1998;39:1524-9.

107 Sethi CS, Limb GA, Charteris DG, et al. Differential expression of matrix metalloproteinases in normal and chronically detached retina. [ARVO Abstract] Invest Ophthalmol Vis Sci 1999;40:S950.

108 Ozerdem U, Cheng LY, Mach-Hofacre B, et al. The effect of AG3340 a potent inhibitor of matrix metalloproteinase on a subacute model of proliferative vitreoretinopathy. Invest Ophthalmol Vis Sci 1999;40:S974.

109 Yang CS, Khawly JA, Hainsworth DP, et al. An intravitreal sustained release triamcinolone and 5-fluorouracil co-drug in the treatment of experimental proliferative vitreoretinopathy. Arch Ophthalmol 1998;116:6977 .

110 Grant MB, Caballero S, Tarnuzzer RW, et al. Matrix metalloproteinase expression in human retinal microvascular cells. Diabetes 1998;47:1311-7.

111 Das A, McGuire PG, Eriqat C, et al. Human diabetic neovascular membranes contain high levels of urokinase and metalloproteinase enzymes. Invest Ophthalmol Vis Sci 1999;40:809-13.

112 Jackson DW, McGuire PG, Eriqat C, et al. Both vascular endothelial growth factor (VEGF) and hypoxia increase gelatinase A (MMP-2) activity in vascular endothelial cells in vitro. [ARVO Abstract] Invest Ophthalmol Vis Sci 1997;38:S500.

113 Kosano H, Okano T, Katsura Y, et al. ProMMP-2 (92 kDa gelatinase) in vitreous fluid of patients with proliferative diabetic retinopathy. Life Sci 1999;64:2307-15

114 Das A, McLamore A, Song W, et al. Retinal neovascularisation is suppressed with a matrix metalloproteinase inhibitor. Arch Ophthalmol 1999;117:498-503.

115 Sawicki G, Sanders EJ, Salas E, et al. Localisation and translocation of MMP-2 during aggregation of human platelets. Thromb Haemost 1998;80: $836-9$.

116 Ryan ME, Ramamurthy MS, Sorsa T, et al. MMP-mediated events in diabetes. Ann NY Acad Sci 1999;878:311-34.

117 Morimoto Y, Nishikawa K, Ohashi M. KB-R7785, a novel matrix metalloproteinase inhibitor, exerts its antidiabetic effect by inhibiting tumour necrosis factor alpha production. Life Sci 1997;61:795-803.

118 McLennan SV, Death AK, Fisher EJ, et al. The role of the mesangial cell and its matrix in the pathogenesis of diabetic nephropathy. Cell Mol Biol $1999 ; 45: 123-35$.

119 Ebihara I, Nakamura $\mathrm{T}$, Shimada $\mathrm{N}$, et al. Increased plasma metalloproteinase-9 concentrations precede development of microalbuminuria in non-insulin-dependent diabetes mellitus. Am f Kidney Dis 1998;32:544-50.

120 Mooy CM, de Jong PTVM. Prognostic parameters in uveal melanoma: a review. Surv Ophthalmol 1996;41:215-28.

121 Mueller BM. Different roles for plasminogen activators and metalloproteinases in melanoma metastasis. Curr Top Microbiol Immunol 1996;212:6580

122 Vaisanen A, Kallioinen $\mathrm{M}$, von Dickhoff $\mathrm{K}$, et al. Matrix metalloproteinase-2 (MMP-2) immunoreactive protein - a new prognostic marker in uveal melanoma? f Pathol 1999;188:56-62.

123 Westermarck J, Kahari VM. Regulation of matrix metalloproteinase expression in tumour invasion. FASEB 7 1999;13:781-92.

124 Lee KS, Rha SY, Kim SJ, et al. Sequential activation and production of matrix metalloproteinase-2 during breast cancer progression. Clin Exp Metastasis 1996;14:512-9. 
125 Werb Z, Vu TH, Rinkenberger JL, et al. Matrix-degrading proteases and angiogenesis during development and tumour formation. APMIS 1999; 107:11-18.

126 Brown PD. Synthetic inhibitors of matrix metalloproteinases. In: Parks WC, Mecham RP, eds. Matrix metalloproteinases. San Diego: Academic Press, 1998:249-52.

127 Anand-Apte B, Bao L, Smith R, et al. A review of tissue inhibitor of metalloproteinase-3 (TIMP-3) and experimental analysis of its effect on primary tumour growth. Biochem Cell Biol 1996;74:853-62.

128 Brown PD. Clinical studies with matrix metalloproteinase inhibitors. APMIS 1999;107:174-80.

129 Lokeshwar BL. MMP inhibition in prostate cancer. Ann NY Acad Sci 1999;878:271-89.

130 Fariss RN, Apte SS, Olsen BR, et al. Tissue inhibitor of metaloproteinase-3 is a component of Bruch's membrane of the eye. Am $\mathcal{f}$ Pathol 1997; 150:323-8.

131 Vranka JA, Johnson E, Zhu X, et al. Discreet expression and distribution pattern of TIMP-3 in the human retina and choroid. Curr Eye Res 1997;16: $102-10$.

132 Anande-Apte B, Pepper MS, Voest E, et al. Inhibition of angiogenesis by tissue inhibitor of metalloproteinase-3. Invest Ophthalmol Vis Sci 1997;38: 817-23.

133 Wang X, Tromp G, Cole CW, et al. Analysis of coding sequences for tissue inhibitor of metalloproteinase 1 (TIMP1) and 2 (TIMP2) in patients with aneurysms. Matrix Biol 1999;18:121-4.

134 Sorsby A, Mason MEJ, Gardener N. A fundus dystrophy with unusual features. Br f Ophthalmol 1949;33:67-97.

135 Chong NHV, Alexander RA, Gin T, et al. TIMP-3, collagen and elastin immunohistochemistry and histopathology of Sorsby's fundus dystrophy. Invest Ophthalmol Vis Sci 2000;41:898-908.

136 Weber BH, Vogt G, Pruett RC, et al. Mutations in the tissue inhibitor of metalloproteinase-3 (TIMP-3) in patients with Sorsby's fundus dystrophy. Nat Genet 1994;8:352-6.

137 Felbor U, Stohr H, Amann T, et al. A second independent Tyr168Cys mutation in the tissue inhibitor of metalloproteinases-3 (TIMP-3) in Sorsby's fundus dystrophy. 7 Med Genet 1996;33:233-6.

138 Jacobson SG, Cideciyan AV, Regunath G, et al. Night blindness in Sorsby's fundus dystrophy reversed by vitamin A. Nat Genet 1995;11:27-32.

139 Apte SS, Mattei MG, Olsen BR. Cloning of the CDNA encoding human tissue inhibitor of metalloproteinase-3 (TIMP-3) and mapping of the tissue inhibitor of metalloproteinase-3 (TIMP-3) and m
TIMP-3 gene to chromosome 22. Genomics 1994;19:86-90.

140 Langton KP, Barker MD, McKie N. Localisation of the functional domains of human tissue inhibitor of metalloproteinase- 3 and the effects of a Sorsby's fundus dystrophy mutation. F Biol Chem 1998;273:16778-81.

141 Fariss RN, Apte SS, Luthert PJ, et al. Accumulation of tissue inhibitor of metalloproteinases-3 in human eyes with Sorsby's fundus dystrophy or retinitis pigmentosa. Br f Ophthalmol 1998;82:1329-34

142 Evans J, Wormald R. Is the incidence of registrable age-related macular degeneration increasing? Br f Ophthalmol 1996;80:2.

143 Bressler NM, Bressler SB, Fine SL. Age-related macular degeneration. Surv Ophthalmol 1988;32:375-413.

144 Felbor U, Doepner D, Schneider U, et al. Evaluation of the gene encoding the tissue inhibitor of metalloproteinases-3 in various maculopathies. Invest Ophthalmol Vis Sci 1997;38:1054-9.

145 De La Paz MA, Pericak-Vance MA, Lennon F, et al. Exclusion of TIMP-3 as a candidate locus in age-related macular degeneration. Invest Ophthalmol Vis Sci 1997;38:1060-5.

146 Kamei M, Hollyfield JG. TIMP-3 in Bruch's membrane: changes during aging and in age-related macular degeneration. Invest Ophthalmol Vis Sci 1999;40:2367-75.
147 Zeiss CJ, Acland GM, Aguirre GD, et al. TIMP-1 expression is increased in X-linked progressive retinal atrophy despite its exclusion as a candidate gene. Gene 1998;225:67-75.

148 Hee MR, Baumal CR, Puliafito CA, et al. Optical coherence tomography of age-related macular degeneration and choroidal neovascularisation. Ophthalmology 1996;103:1260-70.

149 Plantner JJ, Jiang C, Smine A. Increase in interphotoreceptor matrix gelatinase A (MMP-2) associated with age-related macular degeneration. Exp Eye Res 1998;67:637-45.

150 Guo L, Hussain AA, Limb GA, et al. Age-dependent variation in metalloproteinase activity of isolated human Bruch's membrane and choroid. Invest Ophthalmol Vis Sci 1999;40:2676-82.

151 Ali RR, Reichel MB, Hunt DM, et al. Gene therapy for inherited retinal degeneration. Br f Ophthalmol 1997;81:795-801.

152 Ho AC, Maguire MG, Yoken J, et al. Laser-induced drusen reduction improves visual function at 1 year. Ophthalmology 1999;106:1367-74.

153 Ormerod LD, Puklin JE, Frank RN. Long-term outcomes after the surgical removal of advanced subfoveal neovascular membranes in age-related macular degeneration. Ophthalmology 1994;101:1201-10.

154 Adelberg DA, Del Priore LV, Kaplan HJ. Surgery for subfoveal membranes in myopia, angioid streaks, and other disorders. Retina 1995;15:198-205.

155 Steen B, Sejersen S, Berglin L, et al. Matrix metalloproteinases and metalloproteinase inhibitors in choroidal neovascular membranes. Invest Ophthalmol Vis Sci 1998;39:2194-200.

156 Adachi $\mathrm{Y}$, Itoh F, Yamamoto $\mathrm{H}$, et al. Matrix metalloproteinase matrilysin (MMP-7) participates in the progression of human gastric and esophageal cancers. Int $\mathcal{F}$ Oncol 1998;13:1031-5.

157 Kadonosono K, Yazama F, Itoh N, et al. Expression of matrix metalloproteinase-7 in choroidal neovascular membranes in age-related macular degeneration. Am f Ophthalmol 1999;128:382-4.

158 Garcia CR, Rivero ME, Hagedorn M, et al. Efficacy of AG3340, a selective inhibitor of matrix metalloproteases in an animal model of retinal neovascularization. [ARVO Abstract] Invest Ophthalmol Vis Sci 1999;40:S617.

159 Shalinsky DR, Brekken J, Zou H, et al. Broad anti-tumour abd anti-angiogenic activities of AG3340, a potent and selective MMP inhibitor undergoing advanced oncology clinical trials. Ann NY Acad Sci 1999;878: 236-70.

160 Rivero ME, Garcia CR, McDermott CD, et al. Intraocular properties of AG3340, a selective matrix metalloproteinase inhibitor with antiAG3340, a selective matrix metalloproteinase inhibitor with anti-
angiogenic activity. [ARVO Abstract] Invest Ophthalmol Vis Sci 1998;39: S585.

161 Collier MA, Yuen GJ, Bansal SK, et al. A phase I study of the matrix metalloproteinase inhibitor AG3340 given in single doses to healthy volunteers. Proc Am Assoc Cancer Res 1997;38:A1491.

162 Heller RA, Schena M, Chai A, et al. Discovery and analysis of inflammatory disease-related genes using cDNA microarrays. Proc Natl Acad Sci USA 1997;94:2150-5.

163 Spirin KS, Ljubimov AV, Castellon R, et al. Analysis of gene expression in human bullous keratopathy corneas containing limiting amounts of RNA. Invest Ophthalmol Vis Sci 1999;40:3108-15.

164 Peng KW, Morling FJ, Cosset FL, et al. A gene delivery system activatable by disease-associated matrix metalloproteinases. Hum Gene Ther 1997;8: $729-38$.

165 Hua J, Mushel RG. Inhibition of matrix metalloproteinase 9 expression by a ribozyme blocks metastasis in a rat sarcoma model system. Cancer Res 1996;56:5279-84.

166 Woessner JF. Matrix metalloproteinase inhibition: from the Jurassic to the third millenium. Ann NY Acad Sci 1999;878:388-403.

167 Shapiro SD. Mighty mice: transgenic technology "knocks out" questions of matrix metalloproteinase function. Matrix Biol 1997;15:527-33. 